\title{
Growth Mechanism and Surface Structure of Ge Nanocrystals Prepared by Thermal Annealing of Cosputtered GeSiO Ternary Precursor
}

\author{
Bo Zhang, ${ }^{1}$ Yong Xiang, ${ }^{1}$ Santosh Shrestha, ${ }^{2}$ Martin Green, ${ }^{2}$ and Gavin Conibeer ${ }^{2}$ \\ ${ }^{1}$ School of Energy Science and Engineering, University of Electronic Science and Technology of China, Chengdu, Sichuan 611731, China \\ ${ }^{2}$ School of Photovoltaic and Renewable Energy Engineering, University of New South Wales, Sydney, NSW 2052, Australia \\ Correspondence should be addressed to Bo Zhang; bo.zhang@uestc.edu.cn
}

Received 9 February 2014; Accepted 13 April 2014; Published 30 April 2014

Academic Editor: Hongchen Chen Gu

Copyright (C) 2014 Bo Zhang et al. This is an open access article distributed under the Creative Commons Attribution License, which permits unrestricted use, distribution, and reproduction in any medium, provided the original work is properly cited.

Ge nanocrystals ( $\mathrm{Ge}$-ncs) embedded in a $\mathrm{SiO}_{2}$ superlattice structure were prepared by magnetron cosputtering and postdeposition annealing. The formation of spherical nanocrystals was confirmed by transmission electron microscopy and their growth process was studied by a combination of spectroscopic techniques. The crystallinity volume fraction of Ge component was found to increase with crystallite size, but its overall low values indicated a coexistence of crystalline and noncrystalline phases. A reduction of Ge$\mathrm{O}$ species was observed in the superlattice during thermal annealing, accompanied by a transition from oxygen-deficient silicon oxide to silicon dioxide. A growth mechanism involving phase separation of $\mathrm{Ge}$ suboxides $\left(\mathrm{GeO}_{x}\right)$ was then proposed to explain these findings and supplement the existing growth models for Ge-ncs in $\mathrm{SiO}_{2}$ films. Further analysis of the bonding structure of Ge atoms suggested that Ge-ncs are likely to have a core-shell structure with an amorphous-like surface layer, which is composed of $\mathrm{GeSiO}$ ternary complex. The surface layer thickness was extracted to be a few angstroms and equivalent to several atomic layer thicknesses.

\section{Introduction}

During the last couple of years germanium nanocrystals (Gencs) have attracted increasing research interest as a promising material for optoelectronics and charge storage applications [1-5]. To this day, two approaches have been predominantly used for the fabrication of Ge-ncs. One of them is the Stranski-Krastanov growth that produces self-assembled Gencs on foreign substrates or in $\mathrm{Ge} / \mathrm{Si}$ superlattice structures $[6,7]$, while the other one forms crystallites via a classical nucleation process and the produced Ge-ncs are dispersed in a matrix composed of high band gap materials. So far, the most widely studied matrix material is amorphous silica due to its high temperature stability and compatibility to versatile preparation methods [8-12]. In this case, a germanium rich $\mathrm{SiO}_{2}$ layer is first deposited as a precursor for crystallization and then thermal annealing is used to change the precipitation to Ge-ncs at nucleation sites.
In our recent work, we managed to fabricate Ge-ncs embedded in a $\mathrm{SiO}_{2}$ superlattice structure $\left(\mathrm{Ge}-\mathrm{ncs}: \mathrm{SiO}_{2}\right)$ by magnetron cosputtering and postdeposition annealing $[13,14]$. It was confirmed by independent techniques that the Ge-ncs have good crystallinity and their size can be modulated by altering the layer thickness, resulting in tunable optical absorption and luminescence behaviour. These results are quite interesting and open a new perspective to the implementation of Ge-ncs with designed properties. However, despite the tremendous advances in preparation techniques, there is still much scope for systematic studies of this nanocomposite. Since germanium is fairly active in an oxygen environment, the formation process of Ge-ncs in $\mathrm{SiO}_{2}$ thin films could become rather complex and is worth exploring. In the meantime, the understanding of the microstructure of Ge-ncs: $\mathrm{SiO}_{2}$ is still incomplete, particularly the surface region where the atoms of crystallite contact the atoms of oxide matrix. In fact, the surface or interfacial layer 
is believed to have great impact on various properties of nanocrystals, and in turn its structure could be affected by external circumstance [15-17].

In this paper, the growth mechanism and surface structure of Ge-ncs: $\mathrm{SiO}_{2}$ were studied experimentally and theoretically. The formation of spherical Ge-ncs was observed by high resolution lattice image. The structural properties of Gencs were characterized for different growth stages and the evolution of crystallinity volume fraction of Ge component was extracted and analyzed. Meanwhile, the infrared absorption properties of as-deposited and postannealed samples were compared to reveal the variation of chemical composition and stoichiometry of the superlattice during the nanocrystal growth. A possible mechanism was proposed based on the experimental results to make the growth model of Ge-ncs more complete. Furthermore, the microstructure of the surface layer of Ge-ncs: $\mathrm{SiO}_{2}$ was investigated and a simple method was adopted to calculate the thickness of the surface layer.

\section{Materials and Methods}

Ge-ncs: $\mathrm{SiO}_{2}$ were fabricated by RF magnetron sputtering and thermal annealing. The sputtering target was a 4-inch circular fused silica plate uniformly partially covered with a few pieces of fan-shaped Ge strips (99.9999\% purity). The growth chamber was pumped down to a base pressure of $3.0 \times 10^{-4} \mathrm{~Pa}$ and the thin films were deposited at $25 \mathrm{~W}$ power. In order to form a multilayered superlattice, alternative layers of Ge-rich $\mathrm{SiO}_{2}(\mathrm{GeRSiO})$ and a mixture of stoichiometric oxides $\left(\mathrm{GeO}_{2} / \mathrm{SiO}_{2}\right)$ were deposited by argon sputtering and by reactive sputtering with argon and oxygen mixture, respectively. In all the samples, the sputtering time was 6 min for individual GeRSiO layer as well as for individual $\mathrm{GeO}_{2} / \mathrm{SiO}_{2}$ layer. On top of the multibilayer structure a thick $\mathrm{GeO}_{2} / \mathrm{SiO}_{2}$ capping layer was grown to prevent possible penetration of moisture and oxidation of Ge-ncs during storage. The film growth was followed by thermal annealing for different time periods at around $685^{\circ} \mathrm{C}$ in vacuum, in situ in the sputtering chamber.

Ge-ncs and the multilayered thin films were analyzed by a series of characterization techniques. Direct physical evidence of the formation of Ge-ncs was obtained by transmission electron microscopy (TEM). The average crystallite sizes were estimated by glancing incidence $\mathrm{X}$-ray diffraction (XRD) using $\mathrm{Cu} \mathrm{K} \alpha$ radiation $(\lambda=0.154 \mathrm{~nm})$, operating at $45 \mathrm{kV}$ and $40 \mathrm{~mA}$. The glancing angle between the incident $\mathrm{X}$ ray and the sample surface was $0.3^{\circ}$. Raman spectra were measured by a micro-Raman spectrometer in a backscattering configuration. The Ar ion laser has a wavelength of $514.4 \mathrm{~nm}$ and the power of laser was lowered to $2 \mathrm{~mW}$ (spot size of $14 \mu \mathrm{m}^{2}$ ) to avoid any spurious crystallization induced by laser heating. The infrared absorption spectra were measured by Fourier transform infrared spectroscopy (FTIR) with a resolution set at $4 \mathrm{~cm}^{-1}$ to study the chemical composition and stoichiometry of the superlattices. The bonding structure of $\mathrm{Ge}$ atoms was acquired by X-ray photoelectron spectroscopy

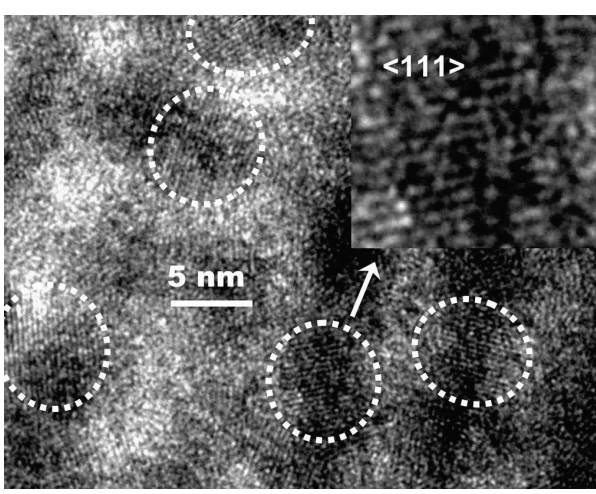

FIgURE 1: TEM image of Ge-ncs embedded in $\mathrm{SiO}_{2}$ matrix. The inset shows lattice fringes inside the Ge-nc indicated by arrow.

(XPS) which employs a monochromatic $\mathrm{Al} \mathrm{K \alpha}(1486.5 \mathrm{eV}) \mathrm{X}$ ray source with a power of $10 \mathrm{kV} \times 12 \mathrm{~mA}$ and a hemispherical energy analyzer.

\section{Results and Discussion}

The direct physical evidence of Ge-ncs produced in glassy oxide matrices was obtained with TEM, as illustrated in Figure 1. Lattice fringes inside the nanocrystals are clearly identified in the inset and their spacing distance is measured to be $\sim 0.33 \mathrm{~nm}$ corresponding to the 111 planes of the Ge diamond structure. It is also noticed that the nanocrystals tended to be spherical in shape although a preferred inplane crystal growth occasionally occurred. However, from this image, it is difficult to determine whether there is an interfacial layer between the crystalline Ge core and the amorphous $\mathrm{SiO}_{2}$ matrix. This might be ascribed to the weak material contrast or the extremely thin thickness of the interfacial layer, which is beyond the resolution of our equipment.

In order to investigate the microstructure evolution of Ge-ncs: $\mathrm{SiO}_{2}$, a group of samples at different growth stages were prepared and characterized. The Raman spectra of superlattices annealed at $685^{\circ} \mathrm{C}$ for different durations are shown in Figure 2. The onset of Ge crystallization was found to take place within the first $6 \mathrm{~min}$ of annealing, but the noticeable amorphous hump indicates that it was still an early stage of crystallite growth. As annealing duration increased, the phonon peaks of Ge-ncs became sharper and narrower, while the amorphous humps were gradually weakened. X-ray diffractograms presented in Figure 3 have been used to calculate the average size of Ge-ncs from the $\{111\}$ peak broadening using the Scherrer equation [18], and the variation of crystallite size with annealing duration is shown in the figure as well. The nanocrystallite size initially increased with annealing duration but approached an upper limit after $15 \mathrm{~min}$. Two mechanisms may be responsible for this phenomenon. First, the thermodynamic equilibrium condition was achieved and higher annealing temperature was required for further nanocrystal growth. On the other hand, it is also possible that the crystallite growth in GeRSiO 


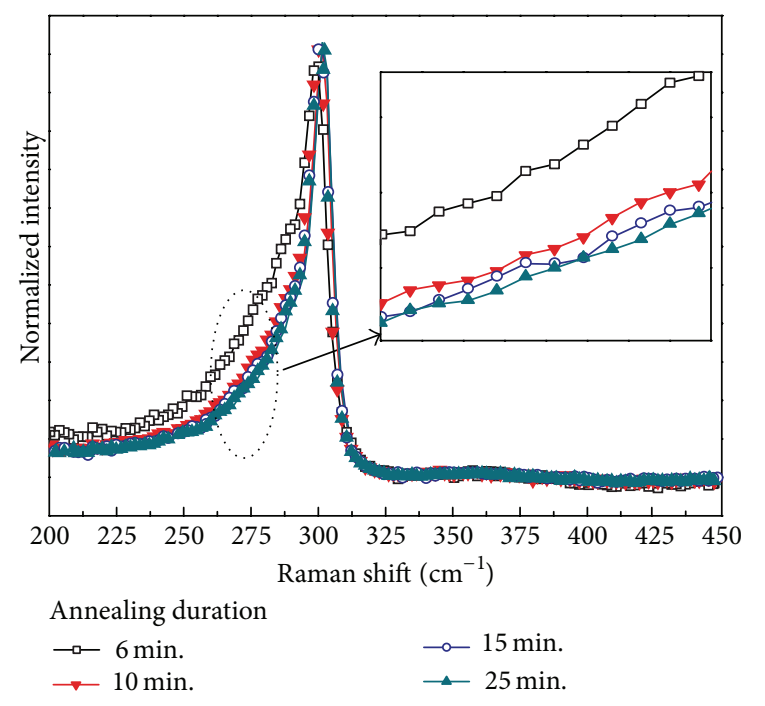

FIGURE 2: Raman spectra of the superlattices annealed at $685^{\circ} \mathrm{C}$ for $6 \mathrm{~min}, 10 \mathrm{~min}, 15 \mathrm{~min}$, and $25 \mathrm{~min}$, respectively.

layers was confined by neighboring $\mathrm{GeO}_{2} / \mathrm{SiO}_{2}$ barrier layers [13].

The crystallinity volume fraction of Ge component in the superlattices was extracted from the Raman spectra in Figure 2 to more deeply probe the nanocrystal growth process. By comparing with as-deposited amorphous film (or, namely, noncrystalline film), the Raman spectra of superlattices containing Ge-ncs can resolve into two parts: the integrated crystalline intensity $I_{c}$ and the integrated amorphous intensity $I_{a}$. The volume fraction of crystallinity $\rho_{c}$ is then obtained by [19]

$$
\rho_{c}=\frac{\rho^{\prime}}{\rho^{\prime}+y\left(1-\rho^{\prime}\right)} \text { with } \rho^{\prime}=\frac{I_{c}}{I_{c}+I_{a}},
$$

where $I_{c}=\sum_{c} \rho_{c}, I_{a}=\sum_{a} \rho_{a}$ ( $\sum$ is the integrated backscattering cross section over the measured frequency range), and $y=\sum_{c} / \sum_{a}$ is the ratio of the integrated Raman cross section of the TO mode of crystalline and amorphous parts. In the case of spherical nanocrystallites with $d$ (diameter) larger than $3 \mathrm{~nm}$, the value of $y$ in (1) can be expressed as [20]

$$
y(d)=0.1+e^{-(d / 250)} .
$$

An example of the decomposition of Raman spectra is illustrated in Figure 4. The fitting curves $I_{c 1}$ (peaks at $299.9 \mathrm{~cm}^{-1}$ ) and $I_{c 2}$ (peaks at $293.2 \mathrm{~cm}^{-1}$ ) belong to the crystalline component, while $I_{\alpha 1}$ (peaks at $276.7 \mathrm{~cm}^{-1}$ ) and $I_{\alpha 2}$ (peaks at $230.9 \mathrm{~cm}^{-1}$ ) belong to the amorphous component. Then $\rho_{c}$ can be calculated using (1) and (2) given the crystallite diameter, or in other words the Scherrer crystallite size. The same treatment has been applied to all the samples and $\rho_{c}$ is plotted in Figure 5 as a function of annealing duration. It is seen that $\rho_{c}$ has a similar variation trend as that of crystallite size, and the low values of $\rho_{c}$ (maximum at $45.5 \%$ ) indicate a coexistence of crystalline and noncrystalline phases in our samples.
The growth of crystallites during thermal annealing demonstrated by Raman and XRD results suggests that the formation of Ge-ncs: $\mathrm{SiO}_{2}$ is within the framework of classical nucleation theory which includes two basic procedures, the diffusion of $\mathrm{Ge}$ atoms or clusters to the nearest nuclei and the continuous formation of Ge-Ge bonds. Even though it seems like a simple concept, the actual growth kinetics could be more complicated and involve some unexpected features. In a further development of the underlying thermodynamics, we investigated the variation of chemical composition and stoichiometry of the superlattices during the nanocrystal growth. The normal incidence infrared absorption spectra were measured from both the as-deposited and postannealed samples as shown in Figure 6. In addition to the characteristic peaks of $\mathrm{SiO}_{2}$ at 436,810 , and $1033 \mathrm{~cm}^{-1}$, the as-deposited sample also shows a peak that can be associated with $\mathrm{Ge}-\mathrm{O}$ defect species at $706 \mathrm{~cm}^{-1}[21,22]$. In contrast, the annealed sample exhibits very different absorption properties. The center of the Si-O-Si asymmetric stretching band shifts from 1033 to $1070 \mathrm{~cm}^{-1}$, while the full width at half maximum (FWHM) of the band decreases from 158 to $92 \mathrm{~cm}^{-1}$. Similar effects are also observed for the absorption band at $436 \mathrm{~cm}^{-1}$. Such blue shift of peak position and decrease of bandwidth are probably attributed to the transition from oxygen-deficient oxide $\left(\mathrm{SiO}_{x}, 1<x<2\right)$ to dioxide in the matrix $[23,24]$. In the meantime, the vanishing of the band at $706 \mathrm{~cm}^{-1}$ after annealing indicates that $\mathrm{O}$-vacancy complex related to $\mathrm{Ge}-\mathrm{O}$ defect species is significantly reduced. Based on these results, we propose an additional mechanism to supplement the former mentioned nucleation growth model. During the cosputtering of the GeRSiO layer, part of the incorporated Ge atoms form chemical bonds with oxygen atoms, thus leading to a substoichiometric thin film composed of $\mathrm{Si}$ suboxide $\left(\mathrm{SiO}_{x}\right)$ and $\mathrm{Ge}$ suboxide $\left(\mathrm{GeO}_{y}\right)$. In the following annealing step, phase separation would occur in Ge suboxide if the temperature is higher than $500^{\circ} \mathrm{C}$ [25-27], and this supplies $\mathrm{Ge}$ atoms for the precipitation of nanocrystals. The overall reaction formula of this process is described as follows:

$$
(2-x) \mathrm{GeO}_{y}+y \mathrm{SiO}_{x} \longrightarrow(2-x) \mathrm{Ge}+y \mathrm{SiO}_{2}
$$

So far the growth mechanism of Ge-ncs: $\mathrm{SiO}_{2}$ is further complemented by the awareness of the presence of $\mathrm{Ge}$ suboxide in the sputtered thin films. It is noted that the oxygen rich environment has a significant impact on the bonding structure of deposited germanium. In the same manner, the surface layer of Ge-ncs formed under high temperature conditions might also have been influenced by the surrounding oxide matrix. Therefore, XPS spectra around the core level Ge3d electrons as displayed in Figure 7 have been employed to examine the bonding structure of $\mathrm{Ge}$ atoms in the annealed samples. Besides the sharp peak corresponding to Ge-ncs (at binding energy of $\sim 29.3 \mathrm{eV}$ ), the spectra exhibit a small hump between $31 \mathrm{eV}$ and $33 \mathrm{eV}$, which can be ascribed to a mixture of Ge substoichiometric oxides $\left(\mathrm{GeO}_{x}\right.$, where $\left.x<2\right)$. Because of aforementioned phase separation effect, we conjecture that these $\mathrm{Ge}-\mathrm{O}$ species are more likely to exist in the surface layer of nanocrystals than in the matrix [28]. In fact, it has been reported that in 


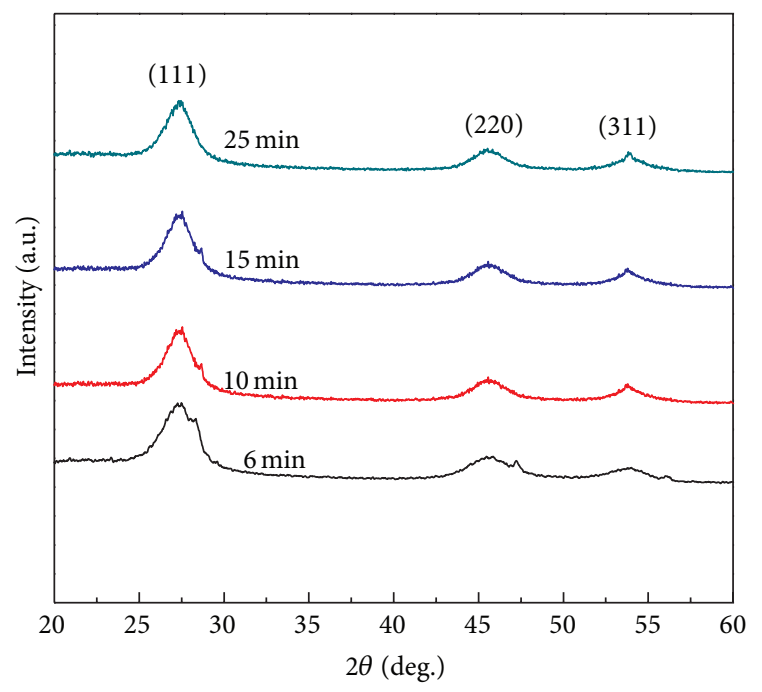

(a)

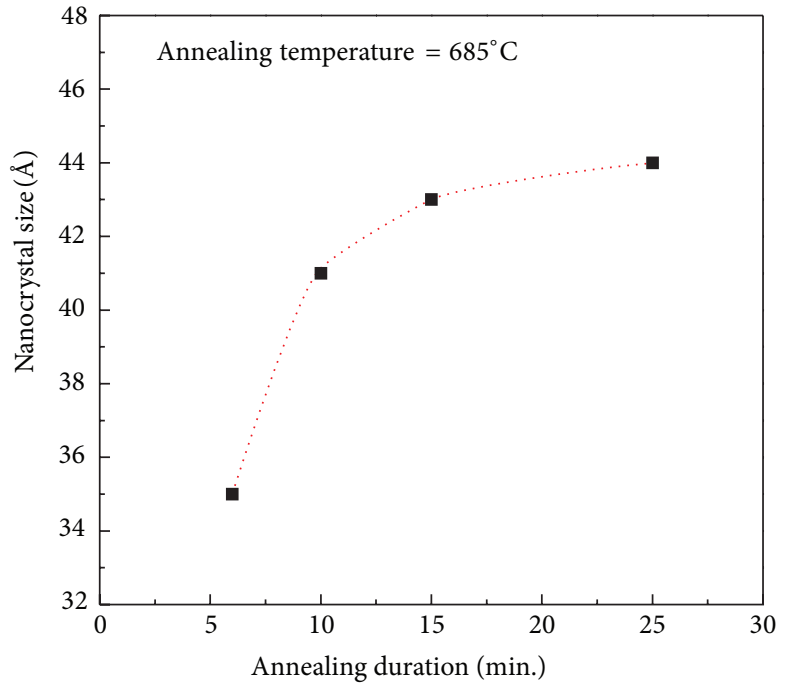

(b)

FIGURE 3: (a) XRD diffractograms of the superlattices annealed at $685^{\circ} \mathrm{C}$ for different annealing durations and (b) average size of Ge-ncs as a function of annealing duration.

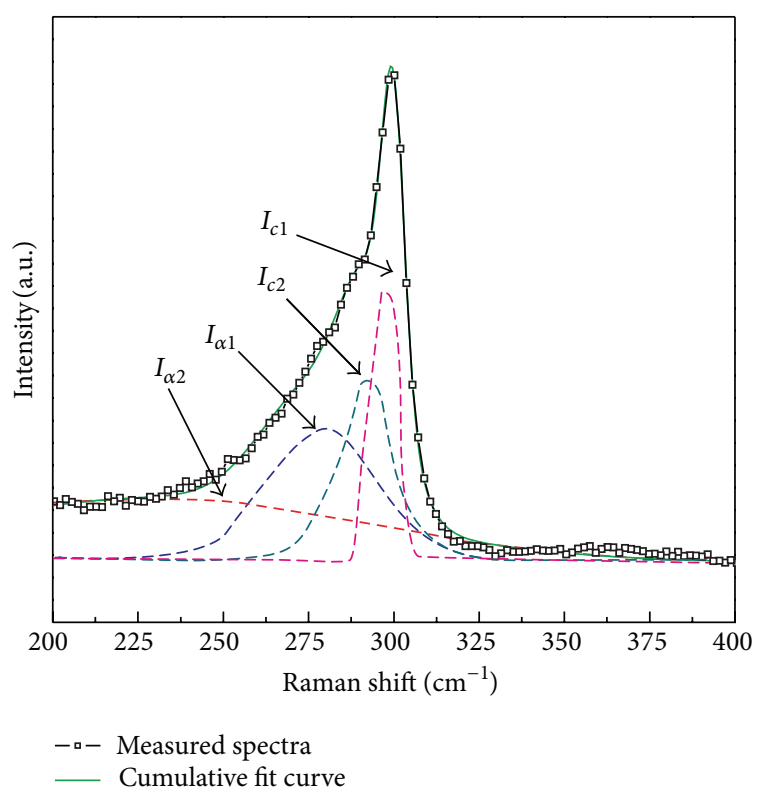

Figure 4: The Gaussian fit of Raman spectra for the sample annealed at $685^{\circ} \mathrm{C}$ for $6 \mathrm{~min}$. Fit curves $I_{c 1}$ and $I_{c 2}$ correspond to the crystalline component while $I_{\alpha 1}$ and $I_{\alpha 2}$ correspond to the amorphous component. During the fit procedure, the peak positions are limited to specific ranges, while other parameters are unbounded.

some circumstances Ge-ncs have a core-shell structure with crystalline core and amorphous shell [29-31]. In our oxygen rich environment, the surface atoms of Ge-ncs tend to be terminated by oxygen atoms. Although the exact bonding structure and atomic number ratio is difficult to determine because of uncertainty in the local chemical composition and stoichiometry, it is still reasonable to expect that a thin layer

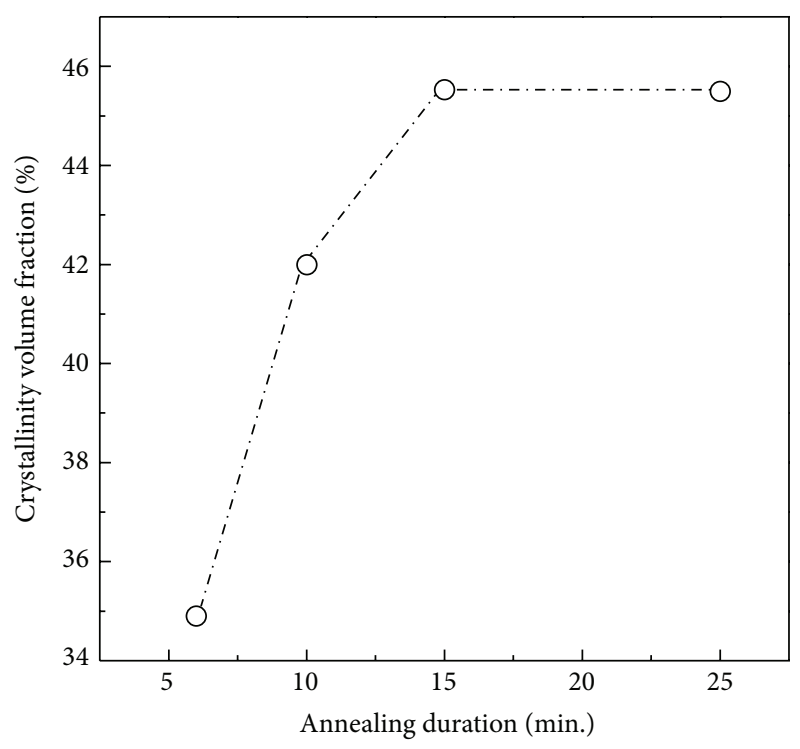

FIGURE 5: The crystallinity volume fraction $\left(\rho_{c}\right)$ of Ge component in the superlattices as a function of annealing duration.

composed of GeSiO ternary complex is likely formed around the crystalline Ge core. An example of the surface structure is schematically illustrated in Figure 8. One thing to note here is the disordering of surface atoms which could be the cause of the amorphous-like vibration modes observed in the Raman spectra of Figure 2. Thus, by assuming that the surface layer is solely responsible for these noncrystalline components, we are able to use the following equation to roughly estimate the surface layer thickness in our Ge-ncs which are fairly spherical in shape:

$$
\rho_{c}=\left[\frac{r_{c}}{\left(r_{c}+t_{s}\right)}\right]^{3} \text {, }
$$




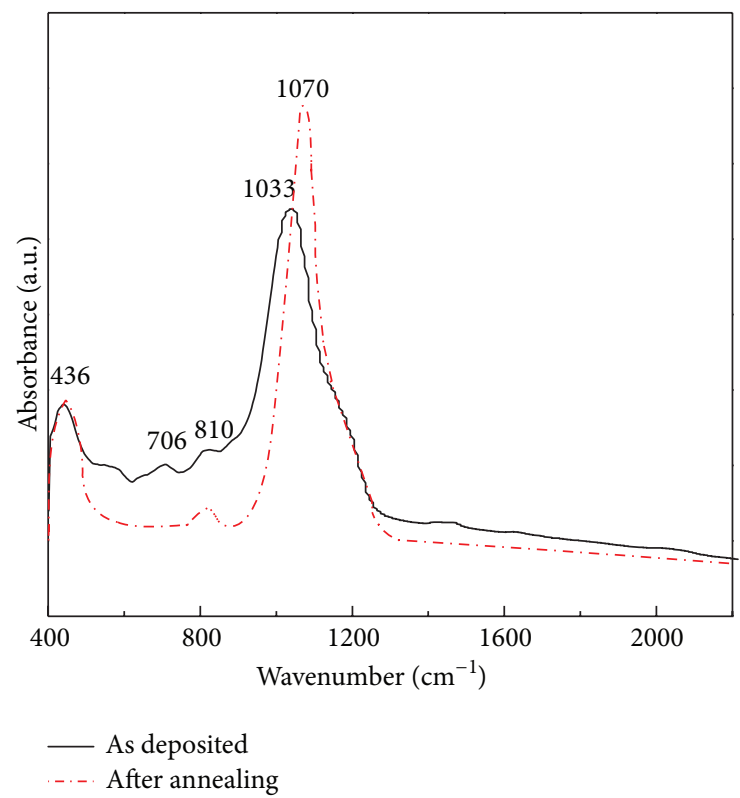

FIGURE 6: FTIR spectra of as-deposited and postannealed superlattices. The numbers label the wavenumbers of different peaks.

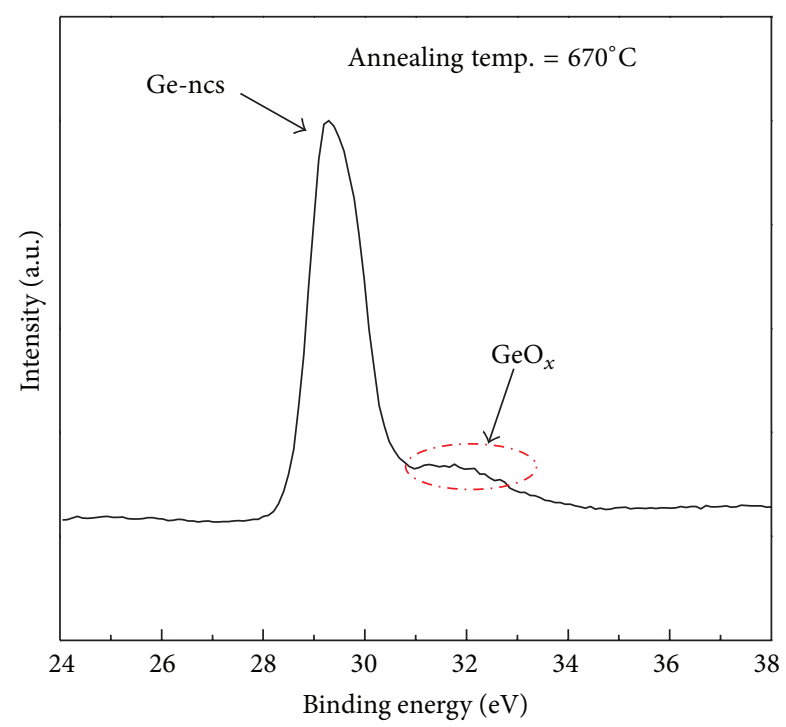

Figure 7: XPS spectra of Ge-ncs: $\mathrm{SiO}_{2}$ annealed at $670^{\circ} \mathrm{C}$ for $25 \mathrm{~min}$. The small hump indicated by dashed ellipse is related to the $\mathrm{Ge}$ suboxide species $\left(\mathrm{GeO}_{x}\right)$.

where $t_{s}$ is the thickness of the surface layer and $r_{c}$ is the radius of the cryptocrystalline Ge-nc core which approximates to half of the crystallite size measured from XRD. The superlattice annealed for $25 \mathrm{~min}$ with a $\rho_{c}$ of $45.5 \%$ has been chosen for the thickness calculation, because the nanocrystal growth process was completed in this sample. The derived thickness of surface layer is about $6.6 \AA$ which is equivalent to a few atomic layer thicknesses and agrees well with previously reported results [29-33]. It should be aware that a thickness of this order of magnitude is very difficult to be detected by the TEM measurement, which explains

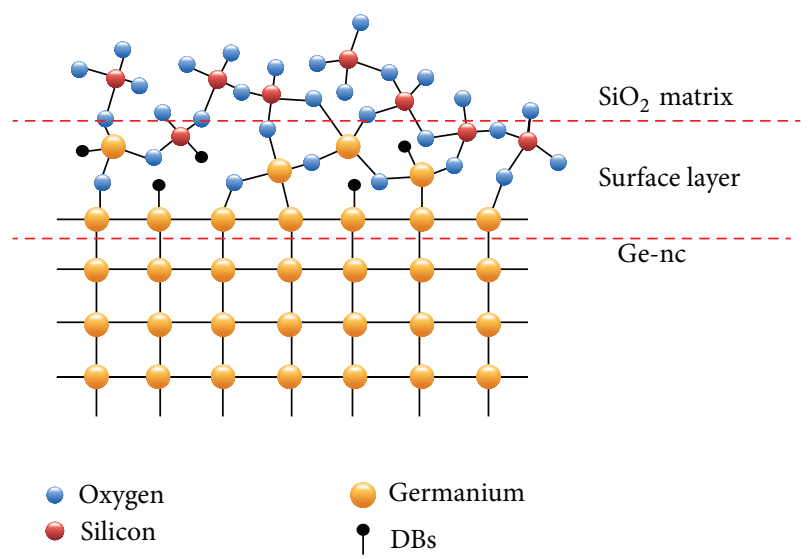

FIgURE 8: Schematic diagram of the surface layer of Ge-ncs:SiO which illustrates the GeSiO ternary component and the dangling bonds (DBs).

why this surface layer is not observed in Figure 1. Moreover, the real thickness of surface layer should be even less than the calculated values, because other components may also contribute to the noncrystalline phase of the superlattices, such as the noncrystallized $\mathrm{Ge}$ atoms or clusters remaining in $\mathrm{SiO}_{2}$ matrix. Nevertheless, we expect that the surface layer effect dominated in our samples.

\section{Conclusions}

Ge-ncs embedded in $\mathrm{SiO}_{2}$ superlattices were fabricated and studied experimentally and theoretically. TEM micrograph confirms the formation of Ge-ncs with spherical shape and diamond structure. A group of samples annealed for different time periods were characterized to enable the understanding of the nanocrystal growth process. The Raman results show that, as annealing proceeded, there was a continuous improvement of film crystallinity. The average sizes of Ge-ncs were calculated from the X-ray peak broadening and it can be inferred that the nanocrystal growth was completed after $25 \mathrm{~min}$ annealing. The crystallinity volume fraction extracted from Raman spectra exhibited a variation tendency similar to that of crystallite size, and its overall low values suggested a coexistence of crystalline and noncrystalline phases in our samples. The measurement of infrared absorption spectra reveals that the Ge-O species was significantly reduced during the nanocrystal growth, and simultaneously the oxygendeficient silicon oxide was changed to silicon dioxide in the matrix. Based on these observations, a growth mechanism involving phase separation of $\mathrm{Ge}$ suboxides $\left(\mathrm{GeO}_{x}\right)$ was developed to supplement the existing growth models for Gencs in $\mathrm{SiO}_{2}$ films. Moreover, the bonding structure of $\mathrm{Ge}$ atoms was examined to study the surface structure of $\mathrm{Ge}$ ncs: $\mathrm{SiO}_{2}$. Preliminary results show that Ge-ncs are likely to have an amorphous-like surface layer composed of $\mathrm{GeSiO}$ ternary complex. The surface layer thickness was further determined from the crystallinity volume fraction and was in the order of angstroms, which is equivalent to a few atomic layer thicknesses. 


\section{Conflict of Interests}

The authors declare that there is no conflict of interests regarding the publication of this paper.

\section{Acknowledgments}

This work was supported by the National Natural Science Foundation of China (Grant no. 61204004), the Fundamental Research Funds for the Central Universities (Grant no. ZYGX2012J157), and the Global Climate and Energy Project (GCEP) administered by Stanford University.

\section{References}

[1] S. Tong, F. Liu, A. Khitun, K. L. Wang, and J. L. Liu, "Tunable normal incidence Ge quantum dot midinfrared detectors," Journal of Applied Physics, vol. 96, no. 1, pp. 773-776, 2004.

[2] M. Scarselli, S. Masala, P. Castrucci et al., "Optoelectronic properties in quantum-confined germanium dots," Applied Physics Letters, vol. 91, no. 14, Article ID 141117, 2007.

[3] Y. Maeda, N. Tsukamoto, Y. Yazawa, Y. Kanemitsu, and Y. Masumoto, "Visible photoluminescence of Ge microcrystals embedded in $\mathrm{SiO}_{2}$ glassy matrices," Applied Physics Letters, vol. 59, no. 24, pp. 3168-3170, 1991.

[4] M. I. Ortiz, A. Rodríguez, J. Sangrador et al., "Luminescent nanostructures based on Ge nanoparticles embedded in an oxide matrix," Nanotechnology, vol. 16, no. 5, pp. S197-S201, 2005.

[5] W. K. Choi, W. K. Chim, C. L. Heng et al., "Observation of memory effect in germanium nanocrystals embedded in an amorphous silicon oxide matrix of a metal-insulatorsemiconductor structure," Applied Physics Letters, vol. 80, no. 11, pp. 2014-2016, 2002.

[6] D. J. Eaglesham and M. Cerullo, "Dislocation-free StranskiKrastanow growth of Ge on Si(100)," Physical Review Letters, vol. 64, no. 16, pp. 1943-1946, 1990.

[7] O. G. Schmidt, O. Kienzle, Y. Hao, and K. Eberl, "Modified Stranski-Krastanov growth in stacked layers of self-assembled islands," Applied Physics Letters, vol. 74, no. 9, pp. 1272-1274, 1999.

[8] D. C. Paine, C. Caragianis, T. Y. Kim, Y. Shigesato, and T. Ishahara, "Visible photoluminescence from nanocrystalline Ge formed by $\mathrm{H}_{2}$ reduction of $\mathrm{Si}_{0.6} \mathrm{Ge}_{0.4} \mathrm{O}_{2}$," Applied Physics Letters, vol. 62, no. 22, pp. 2842-2844, 1993.

[9] K. V. Shcheglov, C. M. Yang, K. J. Vahala, and H. A. Atwater, "Electroluminescence and photoluminescence of Ge-implanted $\mathrm{Si} / \mathrm{SiO}_{2} / \mathrm{Si}$ structures," Applied Physics Letters, vol. 66, no. 6, pp. 745-747, 1995.

[10] A. K. Dutta, "Visible photoluminescence from Ge nanocrystal embedded into a $\mathrm{SiO}_{2}$ matrix fabricated by atmospheric pressure chemical vapor deposition," Applied Physics Letters, vol. 68, no. 9, pp. 1189-1191, 1996.

[11] M. Yamamoto, T. Koshikawa, T. Yasue, H. Harima, and K. Kajiyama, "Formation of size controlled Ge nanocrystals in $\mathrm{SiO}_{2}$ matrix by ion implantation and annealing," Thin Solid Films, vol. 369, no. 1, pp. 100-103, 2000.

[12] M. Buljan, U. V. Desnica, M. Ivanda et al., "Formation of threedimensional quantum-dot superlattices in amorphous systems: experiments and Monte Carlo simulations," Physical Review B, vol. 79, no. 3, Article ID 035310, 2009.
[13] F. Gao, M. A. Green, G. Conibeer et al., "Fabrication of multilayered Ge nanocrystals by magnetron sputtering and annealing," Nanotechnology, vol. 19, no. 45, Article ID 455611, 2008.

[14] B. Zhang, S. Shrestha, P. Aliberti, M. A. Green, and G. Conibeer, "Characterisation of size-controlled and red luminescent Ge nanocrystals in multilayered superlattice structure," Thin Solid Films, vol. 518, no. 19, pp. 5483-5487, 2010.

[15] N. Daldosso, M. Luppi, S. Ossicini et al., "Role of the interface region on the optoelectronic properties of silicon nanocrystals embedded in $\mathrm{SiO}_{2}$," Physical Review B, vol. 68, no. 8, Article ID 085327, 2003.

[16] V. M. Dzhagan, M. Y. Valakh, O. E. Raevska, O. L. Stroyuk, S. Y. Kuchmiy, and D. R. T. Zahn, "The influence of shell parameters on phonons in core-shell nanoparticles: a resonant Raman study," Nanotechnology, vol. 20, no. 36, Article ID 365704, 2009.

[17] C. F. Han and J. F. Lin, "The model developed for stress-induced structural phase transformations of micro-crystalline silicon films," Nano-Micro Letters, vol. 2, no. 2, pp. 68-73, 2010.

[18] I. J. Langford and A. J. C. Wilson, "Scherrer after sixty years: a survey and some new results in the determination of crystallite size," Journal of Applied Crystallography, vol. 11, no. 2, pp. 102113, 1978.

[19] R. Tsu, J. Gonzalez-Hernandez, S. S. Chao, S. C. Lee, and K. Tanaka, "Critical volume fraction of crystallinity for conductivity percolation in phosphorus-doped Si:F:H alloys," Applied Physics Letters, vol. 40, no. 6, pp. 534-535, 1982.

[20] E. Bustarret, M. A. Hachicha, and M. Brunel, "Experimental determination of the nanocrystalline volume fraction in silicon thin films from Raman spectroscopy," Applied Physics Letters, vol. 52, no. 20, pp. 1675-1677, 1988.

[21] L. I. Popova, E. D. Atanassova, D. I. Kolev, and B. M. Nikolova, "IR study of ultrathin plasma $\mathrm{SiO}_{2}$ and plasma treated thermal $\mathrm{SiO}_{2}$ films," Journal of Non-Crystalline Solids, vol. 85, no. 3, pp. 382-392, 1986.

[22] R. W. Whan and H. J. Stein, "Oxygen-defect complexes in germanium," Applied Physics Letters, vol. 3, no. 10, pp. 187-189, 1963.

[23] M. Nakamura, Y. Mochizuki, K. Usami, Y. Itoh, and T. Nozaki, "Infrared absorption spectra and compositions of evaporated silicon oxides $\left(\mathrm{SiO}_{\mathrm{x}}\right)$," Solid State Communications, vol. 50, no. 12, pp. 1079-1081, 1984.

[24] R. N. Pereira, J. S. Jensen, J. Chevallier, B. B. Nielsen, and A. N. Larsen, "Paramagnetic defects and amorphous network reconstruction of magnetron sputtered a- $\mathrm{SiO}_{2}$ : Ge films," Journal of Applied Physics, vol. 102, no. 4, Article ID 044309, 2007.

[25] M. Zschintzsch, N. M. Jeutter, J. von Borany, M. Krause, and A. Mücklich, "Reactive dc magnetron sputtering of $\left(\mathrm{GeO}_{\mathrm{x}}-\mathrm{SiO}_{2}\right)$ superlattices for Ge nanocrystal formation," Journal of Applied Physics, vol. 107, no. 3, Article ID 034306, 2010.

[26] M. Zacharias, J. Bläsing, M. Löhmann, and J. Christen, "Formation of Ge nanocrystals in amorphous $\mathrm{GeO}_{\mathrm{x}}$ and $\mathrm{SiGeO}_{\mathrm{x}}$ alloy films," Thin Solid Films, vol. 278, no. 1-2, pp. 32-36, 1996.

[27] C. J. Sahle, C. Sternemann, H. Conrad et al., "Phase separation and nanocrystal formation in GeO," Applied Physics Letters, vol. 95, no. 2, Article ID 021910, 2009.

[28] T. Hanrath and B. A. Korgel, "Chemical surface passivation of Ge nanowires," Journal of the American Chemical Society, vol. 126, no. 47, pp. 15466-15472, 2004.

[29] I. D. Sharp, Q. Xu, C. Y. Liao et al., "Stable, freestanding Ge nanocrystals," Journal of Applied Physics, vol. 97, no. 12, Article ID 124316, 2005. 
[30] L. L. Araujo, R. Giulian, D. J. Sprouster et al., "Size-dependent characterization of embedded Ge nanocrystals: structural and thermal properties," Physical Review B, vol. 78, no. 9, Article ID 094112, 2008.

[31] L. Z. Liu, X. L. Wu, F. Gao, Y. M. Yang, T. H. Li, and P. K. Chu, "Size-independent low-frequency Raman scattering in Ge-nanocrystal-embedded $\mathrm{SiO}_{2}$ films," Optics Letters, vol. 35, no. 7, pp. 1022-1024, 2010.

[32] L. Pizzagalli, G. Galli, J. E. Klepeis, and F. Gygi, "Structure and stability of germanium nanoparticles," Physical Review B, vol. 63, no. 16, Article ID 165324, 2001.

[33] F. Djurabekova and K. Nordlund, "Atomistic simulation of the interface structure of Si nanocrystals embedded in amorphous silica," Physical Review B, vol. 77, no. 11, Article ID 115325, 2008. 

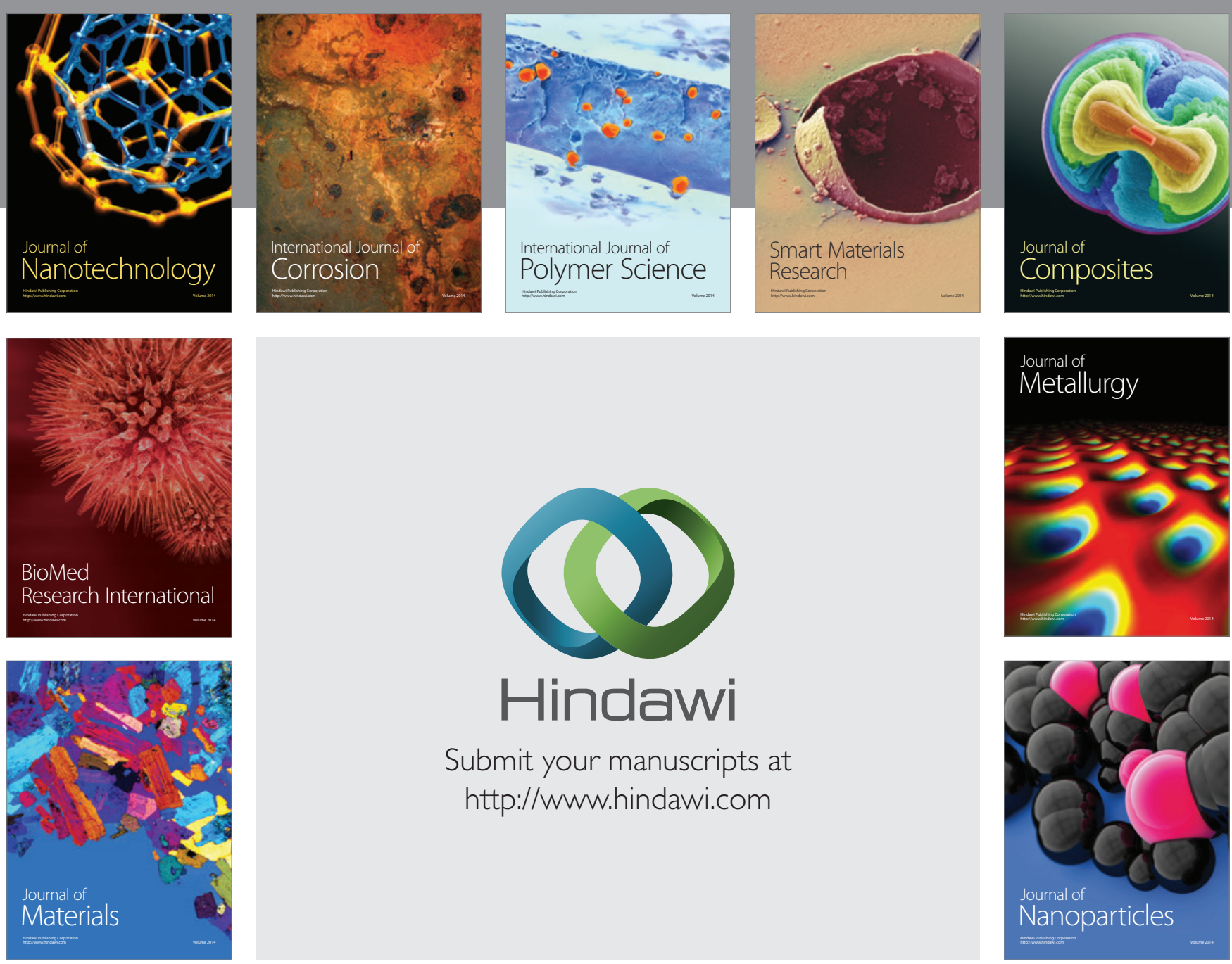

Submit your manuscripts at http://www.hindawi.com
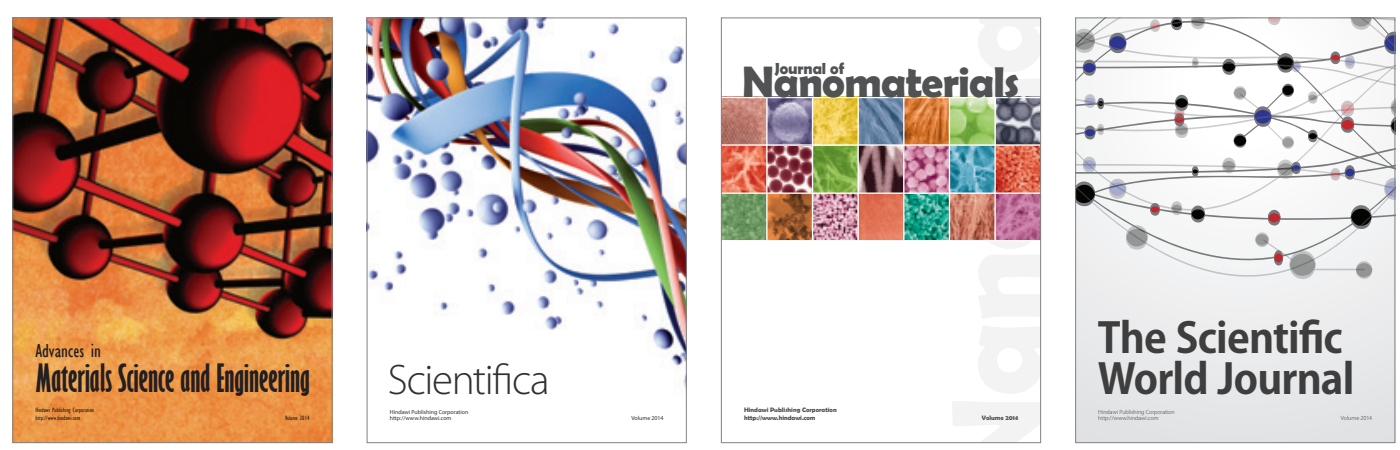

\section{The Scientific World Journal}
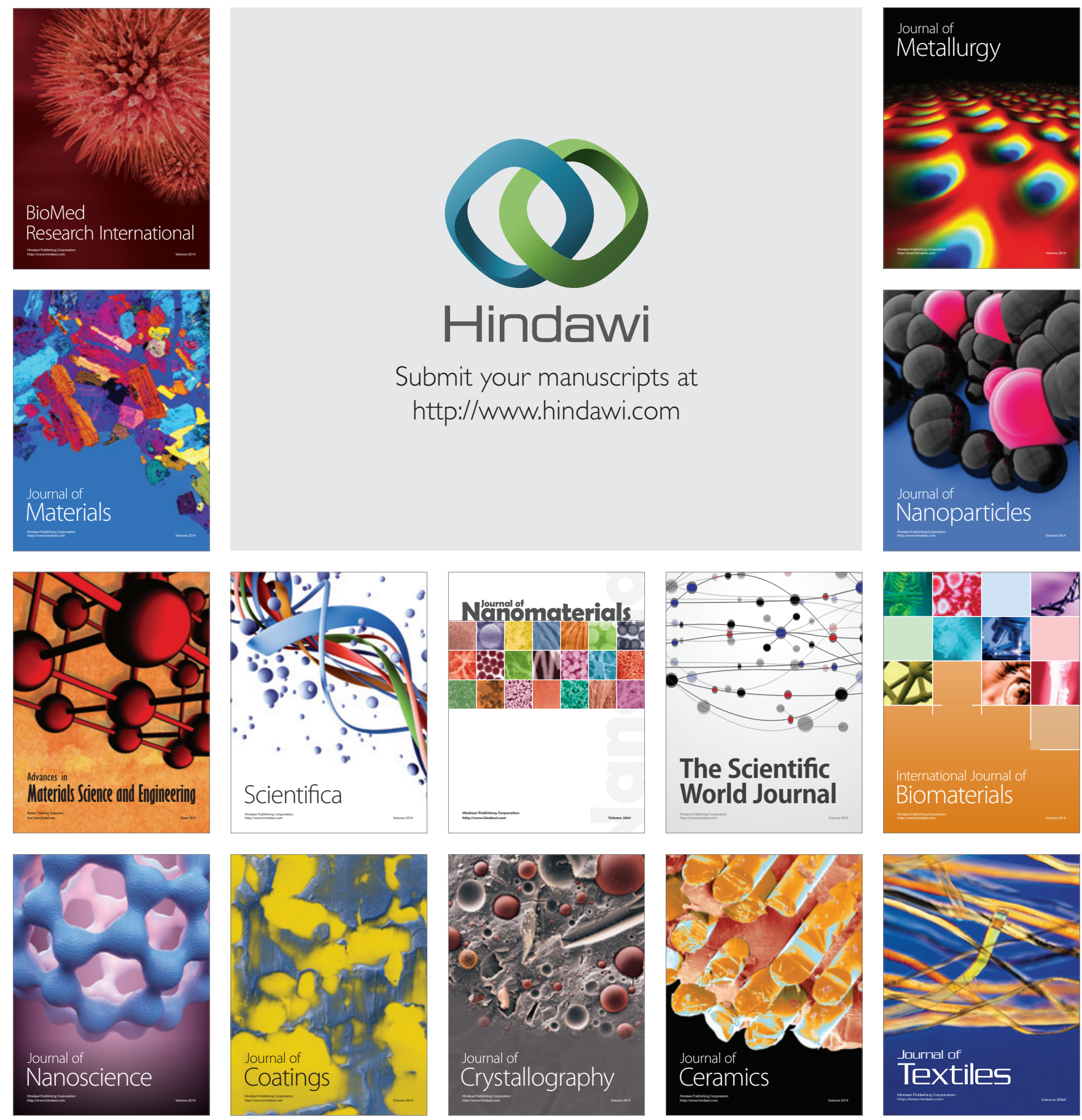